\title{
Regional inequalities in under-5 mortality in Nigeria: a population-based analysis of individual- and community-level determinants
}

\author{
Diddy Antai ${ }^{1,2}$
}

\begin{abstract}
Background: Regions with geographically diverse ecology and socioeconomic circumstances may have different disease exposures and child health outcomes. This study assessed variations in the risks of death in children under age 5 across regions of Nigeria and determined characteristics at the individual and community levels that explain possible variations among regions.

Methods: Multilevel Cox proportional hazards analysis was performed using a nationally representative sample of 6,029 children from 2,735 mothers aged 15-49 years and nested within 365 communities from the 2003 Nigeria Demographic and Health Survey. Hazard ratios (HR) with 95\% confidence intervals (Cl) were used to express measures of association among the characteristics. Variance partition coefficients and Wald statistic were used to express measures of variation.

Results: Patterns of under-5 mortality cluster within families and communities. The risks of under-5 deaths were significantly higher for children of mothers residing in the South South (Niger Delta) region (HR: 1.30; 95\% Cl: 1.762.20) and children of mothers residing in communities with a low proportion of mothers attending prenatal care by a doctor (HR: 1.36; 95\% Cl: 1.15-1.86). In addition, the cross-level interaction between mothers' education and community prenatal care by a doctor was associated with a more than $40 \%$ higher risk of dying (HR: $1.41 ; 95 \% \mathrm{Cl}$ : 1.21-1.78).

Conclusion: The findings suggest the need to differentially focus on community-level interventions aimed at increasing maternal and child health care utilization and improving the socioeconomic position of mothers, especially in disadvantaged regions such as the South South (Niger Delta) region. Further studies on communitylevels determinants of under-5 mortality are needed.
\end{abstract}

\section{Introduction}

The reduction of regional and socioeconomic inequalities in mortality within countries is a major objective of national governments and international organizations [1-3]. To achieve this goal, determinants of high mortality among disadvantaged people, communities, and regions need to be identified. The physical, ecological, and political structure and impoverished socioeconomic milieu in several countries in sub-Saharan Africa account for geographic variations in childhood mortality [4-6]. One such environment is the regional

\footnotetext{
Correspondence: theangelstrust.nigeria@gmail.com

'Division of Global Health \& Inequalities, The Angels Trust - Nigeria, Abuja, Nigeria

Full list of author information is available at the end of the article
}

environment. Poor or polluted environments tend to expose children to disease-causing agents, predisposing them to high mortality risks [7]. In Nigeria, marked regional disparities in mortality of children under age 5 have been reported, with higher rates observed in the Northern regions than in the Southern regions [8-10]. However, these were survey reports rather than empirical studies, and the role of explanatory factors was not investigated. Regional disparities in health-seeking behavior have been reported regarding child immunizations [11], maternal and child health care utilization [12], differences in the socioeconomic composition [13], communicable diseases [13], childhood nutrition, and malnutrition [14]. Other studies have reported that the Northern regions have higher proportions of home
C Biomed Central

(ㄷ) 2011 Antai; licensee BioMed Central Ltd. This is an Open Access article distributed under the terms of the Creative Commons Attribution License (http://creativecommons.org/licenses/by/2.0), which permits unrestricted use, distribution, and reproduction in any medium, provided the original work is properly cited. 
delivery and complications during childbirth [15], younger age of first marriage, younger age at birth of first child, and lower knowledge and use of contraception compared to the Southern regions [16].

Regional disparities in these parameters are associated with factors at the community level that distinguish these regions from each other. The availability of services and social amenities in communities, or the lack thereof, may positively or negatively influence the health of the residents of communities. Some of these factors include differences in community-level development, population density, prevalence of poverty, and availability of maternal and child health care services. These are often interrelated aspects of the regional environment that are important for child health and well-being, and may also be relevant in exacerbating or mitigating inequities in resources and population health outcomes across regions [7]. Regions may either exert more independence and autonomy within nations (in which case they become even more salient for child health), or may exhibit greater centralization (in which case regional factors may not be as significant) [7]. A classic example of attempts to attain the former is the South South (Niger Delta) region in Nigeria [17]. This study contributes to a better understanding of how regional disparities in social services and health-seeking behavior influence inequalities in child survival. The aims of this study are two-fold: 1) to determine whether there is significant variation in the risks of under- 5 deaths across regions of Nigeria; and 2) to determine the individual- and community-level factors that explain disparities in the risks of under- 5 deaths among regions.

\section{Data and Methods}

Cross-sectional data from the 2003 Nigeria Demographic and Health Survey (DHS) were used in this study. This is a nationally representative sample collected by face-to-face interviews from 3,725 women aged 15 to 49 years with a stratified two-stage cluster sampling procedure. An extensive report of the survey can be found elsewhere [18]. Birth history data, such as month and year of birth, survivorship status, and current age or age at death if the child had died were collected for each birth. This sample contained a total of 6,029 live-born children, limited to births in the last five years before the survey to ensure that the household variables investigated provided a close enough or accurate picture of the current living conditions of the children within period they were exposed to increased risks of death.

\section{Ethical considerations}

This study is based on analysis of secondary DHS data with all respondent identifiers removed. The survey was approved by the National Ethics Committee in the Federal Ministry of Health of Nigeria and the Ethics Committee of the Opinion Research Corporation Macro International, Inc. (ORC Macro Inc., Calverton, MD, USA).

\section{Measurements}

\section{Outcome variable}

The outcome variable was the risk of under- 5 death (0-59 months), defined as a child dying between birth and the 5th birthday. Under-5 mortality was estimated for the five years preceding the survey. All children between 0 and 59 months of age were included in the estimation and exposure time, and cases were observed during this time frame, with all living children 59 months or younger being considered as exposures, contributing person-time, and all deaths among children 59 months or younger regarded as cases. Children born during the time frame (at birth) or before the time frame (at any age until 59 months) could enter this time frame. Children who stayed alive after 59 months of age within this time frame were removed from the sample after 59 months of age.

\section{Exposure variables}

Region of residence of the mother was the main exposure variable, categorized as five sets of dummy variables: a) North Central, b) North East, c) North West, d) South East, and e) South South. The regions were comprised of the following states: North Central region (Benue, Kogi, Kwara, Nasarawa, Niger, Plateau states, and Federal Capital Territory, Abuja); North East region (Adamawa, Bauchi, Borno, Gombe, Taraba, and Yobe states); North West region (Jigawa, Kaduna, Kano, Katsina, Kebbi, Sokoto, and Zamfara states); South East region (Abia, Anambra, Ebonyi, Enugu, and Imo states); South South region (Akwa Ibom, Bayelsa, Cross River, Delta, Edo, and Rivers states); and South West region (Ekiti, Lagos, Ogun, Ondo, Osun, and Oyo states).

Explanatory factors: Eight additional individual-level factors of interest were examined: $i$ ) birth order, consisting of two dummy variables: $a$ ) first births and $b$ ) $5^{\text {th }}$ or higher birth order; ii) sex of the child, female; iii) mother's age, consisting of two dummy variables: a) 15-23 years and b) 34 years or older; $i v$ ) mother's age at birth of first child, 18 years or younger; $v$ ) marital status, consisting of two dummy variables: a) single and b) divorced; vi) religious affiliation, made up of two dummy variables: a) Muslim and b)traditional; vii) mother's education, consisting of two dummy variables: a) no education and b) primary education; and viii) wealth index, consisting of two dummy variables: a) poorer wealth quintile and $b$ ) richer wealth quintile. Wealth index was applied in this analysis as a composite 
index and an indicator of the socioeconomic status of households because the DHS does not generally collect information on household income or wealth. It is consistent with expenditure and income measures in low- and middle-income countries. It assigns weights or factor scores generated by principal component analysis to information on household assets collected from censuses and surveys. These indicators include those relating to household ownership of durable assets and household environmental conditions. Principal components analysis allows each asset owned to be given a score, and the factor loading scores are used to create linear composites of each household socioeconomic status variable. The scores are then summed and divided into quintiles (poor, middle, and rich) to represent different levels of wealth.

Cross-level interactions between individual- and community-level measures of socioeconomic position provide the opportunity to explore whether communitylevel effects are different for children of mothers in low socioeconomic position. Interaction effects were assessed as a) cross-level interaction between mother's age at birth of first child and community prenatal care by doctor; and $b$ ) cross-level interaction between mother's education and community prenatal care by doctor.

Three community-level factors were assessed: i) level of mother's education in the community, defined as the percentage of mothers with secondary or higher education in the primary sampling unit (PSU), consisting of two subsets of dummy variables: $a$ ) low and $b$ ) high. This variable was selected because higher levels of maternal education are associated with better child health outcomes like childhood mortality and child immunization rates $[19,20]$. Thus, the proportion of mothers with secondary or higher education is a predictor of child survival.

The second community-level factor assessed was: ii) community hospital delivery, defined as the percentage of mothers who delivered their children in the hospital in the PSU, consisting of two subsets of dummy variables: $a$ ) low and $b$ ) high. And the third communitylevel factor assessed was: iii) community prenatal care by doctor, defined as the percentage of mothers who had prenatal care provided by a doctor, consisting of the dummy variable low. Prenatal care directly increases the chances that mothers would access subsequent health care services for their children, such as delivery in a health institution as well as mother and child immunization [21,22]. Hospital delivery is also one of the most important preventive measures against poor maternal and child health outcomes and an important determinant of full immunization [23,24]. Hence, the proportion of mothers that received prenatal care and the proportion that delivered in a hospital setting are both salient predictors of child survival.

The contextual variables were at the level of the PSU $(n=365)$. Primary sampling units are small, administratively defined areas designed to be fairly homogeneous units in relation to population-level socio-demographic characteristics, economic status, and living conditions. They are used as proxies for "neighborhoods" or "communities" [25,26] and contain one or more enumeration areas, which are the smallest geographic units for which census data are available in Nigeria. Each cluster consisted of a minimum of 50 households, with a contiguous enumeration area added when a cluster had fewer than 50 households [18].

\section{Statistical analysis}

The distribution of the individual- and community-level characteristics in the sample was assessed separately by region of residence in order to assess the unadjusted effect of these characteristics on region of residence. Data were analyzed using Multilevel Cox proportional hazards analysis [27], which models censored time-untilevent data as a dependent variable where one can assume that the covariates have a multiplying effect on hazard rates and warrants recoding characteristics in dummy variables. The associations among under-5 mortality and individual- and community-level characteristics were assessed separately (in order to show how regional variation is built up from variation on various levels) as well as successively. Measures of association (fixed effects) are expressed as hazard ratios (HR), 95\% confidence intervals (95\% CIs) and $p$-value. Measures of variation (random effects) are expressed as intraclass correlation (ICC), which is a measure of the relatedness of clustered data. Generalized linear and latent mixed models (gllamm) were used to perform the three-level multilevel analysis using Stata version 10.0 [28].

Four models were fitted in the analysis containing individual- and community-level characteristics. Model 0 (empty model) contained no explanatory variable since its role was to decompose the total variance into its individual- and community-level components, and to identify a possible contextual phenomenon that can be quantified by clustering of under -5 mortality within neighborhoods [29]. Model 1 contained region of residence as the only explanatory variable to assess the gross effects of region of residence before netting out the effects of other variables, and Model 2 added sex of the child and birth order. Model 3 included the motherlevel variables (mother's age, mother's age at birth of first child, marital status, religious affiliation, mother's education, wealth index, and cross-level interactions between community prenatal care by doctor and mother's age at birth of first child as well as mother's 
education). Finally, Model 4 added community-level variables (community mother's education, community hospital delivery, and community prenatal care by a doctor). The simultaneous inclusion of both individualand neighborhood-level predictors in the multilevel Cox regression model permits: $i$ ) the examination of neighborhood or area effects after individual-level confounders have been controlled for; ii) the examination of individual-level characteristics as modifiers of the area effect (and vice versa); and iii) the simultaneous examination of within- and between neighborhood variability in outcomes, and of the extent to which between-neighborhood variation is explained by individual- and neighborhood-level characteristics [30,31].

\section{Results}

\section{Characteristics of children and women by region of residence}

Examination of individual-level characteristics across regions of residence showed that children in the Northern regions constituted most of the study sample. Mothers who were Christians and had secondary or higher education were most likely from the Southern regions, while mothers from the Northern regions were mostly Muslims, in the middle and poor wealth quintiles, and were 18 years or younger at the birth of their first child (Table 1). The assessment of community-level characteristics across regions of residence in the study sample indicated that children in the Northern regions constituted most of the study sample. Most of the mothers in the North East and North West regions lived in communities with a low proportion of mothers who attended prenatal care by a doctor, while most of the mothers in the North Central and North East regions lived in communities at the median community level in regard to the proportion of mothers who had hospital delivery, as well as the proportion of mothers with secondary or higher education. In contrast, most of the mothers in the Southern regions lived in communities with a high proportion of mothers who attended prenatal care by a doctor, and within the South East and South West regions, in communities with a high proportion of mothers who had hospital deliveries. Mothers in the North Central and North East regions who lived in communities with the proportion of secondary or higher education at the median level for the community made up most in the sample (Table 2).

\section{Risk factors of under-5 mortality}

The risk factors for under- 5 five mortality by region of residence were controlled separately for individual-level factors, and findings showed that the risks of under-5 deaths were almost twofold higher for children of mothers residing in the North East (HR: 1.72; 95\% CI:
1.14 - 2.59); North West (HR: 1.71; 95\% CI: 1.13 - 2.57); and South South (HR: 1.91; 95\% CI: 1.21 - 3.02) regions compared with children of mothers in the South West region. The risks of dying were higher for children of $\geq$ 5 birth order (HR: 1.58; 95\% CI: 1.23 - 2.02); children of mothers with no education (HR: 1.63; 95\% CI: 1.21 2.19) or primary education (HR: 1.60; 95\% CI: 1.21 2.13 ); and in the poor wealth quintile (HR: 1.28 ; $95 \% \mathrm{CI}$ : 1.02 - 1.59). In contrast, the risks of dying were lower for children of mothers in the middle wealth quintile (HR: 0.70; 95\% CI: 0.54 - 0.92) (Table 3).

The risk factors for under- 5 mortality by region of residence also were controlled separately for community-level factors. Children of mothers resident in the South South region had a $15 \%$ higher risk of under-5 death (HR: 1.15; 95\% CI: 1.06 - 1.90) compared to children of mothers in the South West region. In addition, the risks of dying were higher for children resident in communities with a low proportion of mothers who attended prenatal care by a doctor (HR: 1.68 ; 95\% CI: 1.46 - 1.98) and who had hospital delivery (HR: 1.34; 95\% CI: 1.04 - 1.72), while the risks of dying were lower for children resident in communities with a high proportion of hospital delivery (HR: 0.66; 95\% CI: 0.44 0.98) (Table 4).

The risk factors for under- 5 mortality by region of residence were also controlled simultaneously for individualand community-level factors. Region of residence was included as the only explanatory variable in Model 1 to assess the independent influence of region of residence on the risks of under-5 deaths, and was significantly associated with the risks of under- 5 deaths, with about twofold higher risks for children of mothers resident in the North East (HR: 2.41; 95\% CI: 1.63 - 3.57), North West (HR: 2.28; 95\% CI: 1.56 - 3.34), and South South (HR: 1.85; 95\% CI: 1.17 - 2.91) compared with children of mothers resident in the South West region. The risks of under-5 deaths were attenuated with the inclusion of child, mother, and community characteristics; in the final model (Model 4), children of mothers resident in the South South region had 30\% higher risks of dying (HR: 1.30; 95\% CI: 1.76 2.20) compared with children of mothers resident in the South West region (Table 5).

Furthermore, children of $\geq 5$ birth order and of divorced mothers had 24\% (HR: 1.24; 95\% CI 1.24 2.17) and 76\% (HR: 1.76; 95\% CI 1.09 - 2.84) higher risks of under-5 deaths compared with children of $2^{\text {nd }}$ $4^{\text {th }}$ birth order and married mothers, respectively. The risks were more than twofold higher for children of mothers with no education (HR: 2.17 ; 95\% CI 1.44 3.26), and almost twofold higher for children of mothers with primary education (HR: 1.90; 95\% CI 1.32 - 2.75) compared with children of mothers with secondary or higher education. The cross-level interaction between 
Table 1 Distribution of individual-level characteristics by region of residence

\begin{tabular}{|c|c|c|c|c|c|c|c|}
\hline \multirow[t]{2}{*}{ Characteristics } & \multicolumn{6}{|c|}{ Region of residence } & \multirow{2}{*}{$\begin{array}{l}\text { Total } \\
\text { N (\%) }\end{array}$} \\
\hline & $\begin{array}{c}\text { North Central } \\
\text { N (\%) }\end{array}$ & $\begin{array}{l}\text { North East } \\
\mathrm{N}(\%)\end{array}$ & $\begin{array}{c}\text { North West } \\
\mathrm{N}(\%)\end{array}$ & $\begin{array}{c}\text { South East } \\
\mathrm{N}(\%)\end{array}$ & $\begin{array}{c}\text { South South } \\
\text { N (\%) }\end{array}$ & $\begin{array}{c}\text { South West } \\
\mathrm{N}(\%)\end{array}$ & \\
\hline Region of residence & $1,015(17)$ & $1,487(25)$ & $1,821(30)$ & $524(9)$ & $560(9)$ & $622(10)$ & $6029(100)$ \\
\hline Birth order & & & & & & & $* * *$ \\
\hline First birth & $210(21)$ & $240(16)$ & 349 (19) & $99(19)$ & $136(24)$ & $166(27)$ & $1,200(20)$ \\
\hline 2 - 4 birth order & $473(46)$ & $603(41)$ & $759(42)$ & $255(49)$ & $244(44)$ & $317(51)$ & $2,621(43)$ \\
\hline$\geq 5$ birth order & $332(33)$ & $644(43)$ & $713(39)$ & $200(38)$ & $180(32)$ & $139(22)$ & 2,208 (37) \\
\hline Sex of the child & & & & & & & $* * *$ \\
\hline Female & $492(49)$ & $756(51)$ & $915(50)$ & $283(54)$ & $281(50)$ & $335(54)$ & $3,062(51)$ \\
\hline Male & $523(51)$ & 731 (49) & $906(50)$ & $241(46)$ & $279(50)$ & $287(46)$ & 2,967 (49) \\
\hline Mother's age & & & & & & & $* * *$ \\
\hline$\leq 23$ years & $220(22)$ & $396(27)$ & $529(29)$ & $62(12)$ & $118(21)$ & $86(14)$ & $1,411(23)$ \\
\hline $24-33$ years & $556(55)$ & $716(48)$ & $877(48)$ & $269(51)$ & $290(52)$ & $362(58)$ & $3,070(51)$ \\
\hline$\geq 34$ years & $239(23)$ & $375(25)$ & $415(23)$ & $193(37)$ & $152(27)$ & $174(28)$ & $1,548(26)$ \\
\hline Mothers' age at birth of first child & & & & & & & $* * *$ \\
\hline 18 years or less & $516(51)$ & $998(67)$ & $1258(69)$ & $147(28)$ & $280(50)$ & $138(22)$ & $3,337(55)$ \\
\hline 19 years or more & $499(49)$ & $489(33)$ & $563(31)$ & $377(72)$ & $280(50)$ & $484(78)$ & $2,692(45)$ \\
\hline Marital status & & & & & & & $* * *$ \\
\hline Single & $25(2)$ & $7(0)$ & $3(0)$ & $13(3)$ & $49(9)$ & $12(2)$ & $109(2)$ \\
\hline Married & $956(94)$ & $1,421(96)$ & $1,775(97)$ & $477(91)$ & $481(86)$ & $598(96)$ & $5708(95)$ \\
\hline Divorced & $34(4)$ & $59(4)$ & $43(3)$ & $34(6)$ & $30(5)$ & $12(2)$ & $212(3)$ \\
\hline Religious affiliation & & & & & & & $* * *$ \\
\hline Christian & $592(58)$ & $215(15)$ & $111(6)$ & $482(92)$ & $540(97)$ & $367(59)$ & 2307 (38) \\
\hline Muslim & $392(39)$ & $1257(84)$ & $1701(93)$ & $0(0)$ & $7(1)$ & $241(39)$ & $3598(60)$ \\
\hline Traditional & $31(3)$ & $15(1)$ & $9(1)$ & $42(8)$ & $13(2)$ & $14(2)$ & $124(2)$ \\
\hline Mothers' education & & & & & & & $* * *$ \\
\hline No education & $416(41)$ & $1,032(69)$ & 1,338 (73) & $90(17)$ & $52(9)$ & $105(17)$ & $3033(50)$ \\
\hline Primary & $355(35)$ & $263(18)$ & $248(14)$ & $210(40)$ & $195(35)$ & $202(32)$ & $1473(25)$ \\
\hline Secondary or higher & $244(24)$ & $192(13)$ & $235(13)$ & $224(43)$ & $313(56)$ & $315(51)$ & $1523(25)$ \\
\hline Wealth Index & & & & & & & $* * *$ \\
\hline Poor & $425(42)$ & $866(58)$ & $876(48)$ & $214(41)$ & $180(32)$ & $166(27)$ & $2,727(45)$ \\
\hline Middle & $440(43)$ & $524(36)$ & $762(42)$ & $203(39)$ & $238(43)$ & $147(24)$ & 2,332 (39) \\
\hline Rich & $150(15)$ & $79(6)$ & $183(10)$ & $107(20)$ & $142(25)$ & 309 (49) & $970(16)$ \\
\hline
\end{tabular}

${ }^{*} p<.05 ;{ }^{* *} p<.01 ;{ }^{* * *} p<.001$.

Table 2 Distribution of community-level characteristics by region of residence

\begin{tabular}{|c|c|c|c|c|c|c|c|}
\hline Characteristics & North Central N (\%) & $\begin{array}{c}\text { North East } \\
\mathrm{N}(\%)\end{array}$ & $\begin{array}{c}\text { North West } \\
\mathrm{N}(\%)\end{array}$ & $\begin{array}{c}\text { South East } \\
\mathrm{N}(\%)\end{array}$ & $\begin{array}{c}\text { South South } \\
\mathrm{N}(\%)\end{array}$ & $\begin{array}{c}\text { South West } \\
\mathrm{N}(\%)\end{array}$ & $\begin{array}{c}\text { Total } \\
\mathrm{N}\end{array}$ \\
\hline Community mother's education & & & & & & & $* * *$ \\
\hline Low & $93(9)$ & $485(33)$ & $797(44)$ & $70(13)$ & $53(9)$ & $116(19)$ & 1,614 \\
\hline Middle & $510(50)$ & $821(55)$ & $841(46)$ & $205(39)$ & $263(47)$ & $252(40)$ & 2,892 \\
\hline High & $412(41)$ & $181(12)$ & $183(10)$ & $259(48)$ & $244(44)$ & $254(41)$ & 1,523 \\
\hline Community hospital delivery & & & & & & & $* * *$ \\
\hline Low & $88(9)$ & $543(36)$ & $866(48)$ & $8(1)$ & $2(0)$ & $8(1)$ & 1,515 \\
\hline Middle & $640(63)$ & $869(59)$ & $891(49)$ & $134(26)$ & $317(57)$ & $154(25)$ & 3,005 \\
\hline High & $287(28)$ & $75(5)$ & $64(3)$ & $382(73)$ & $241(43)$ & $460(74)$ & 1.509 \\
\hline Community prenatal care by doctor & & & & & & & $* * *$ \\
\hline Low & $511(50)$ & $1,349(91)$ & $1,774(97)$ & $78(15)$ & $61(11)$ & 81 (13) & 3,854 \\
\hline High & $504(50)$ & $138(9)$ & 47 (3) & 446 (85) & 499 (89) & 541 (87) & 2,175 \\
\hline
\end{tabular}

${ }^{*} p<.05 ;{ }^{* *} p<.01 ;{ }^{* * *} p<.001$. 
Table 3 Odds ratios and $95 \%$ confidence intervals for individual-level risk factors for under-5 mortality and region of residence

\begin{tabular}{|c|c|}
\hline Characteristics & OR $(95 \% \mathrm{Cl})$ \\
\hline \multicolumn{2}{|l|}{ Region of residence } \\
\hline North Central & $1.25(0.83-1.88)$ \\
\hline North East & $1.72(1.14-2.59)$ \\
\hline North West & $1.71(1.13-2.57)$ \\
\hline South East & $1.14(0.71-1.84)$ \\
\hline South South & $1.91(1.21-3.02)$ \\
\hline South West & 1 \\
\hline \multicolumn{2}{|l|}{ Sex of child } \\
\hline Female & $1.08(0.92-1.26)$ \\
\hline Male & 1 \\
\hline \multicolumn{2}{|l|}{ Birth order } \\
\hline First birth (order 1) & $1.27(1.00-1.61)$ \\
\hline 2 - 4 birth order & 1 \\
\hline$\geq 5$ birth order & $1.58(1.23-2.02)$ \\
\hline \multicolumn{2}{|l|}{ Mother's age } \\
\hline$\leq 23$ years & $1.03(0.82-1.31)$ \\
\hline $24-28$ years & 1 \\
\hline$\geq 34$ years & $0.96(0.74-1.26)$ \\
\hline \multicolumn{2}{|l|}{ Mother's age at birth of first child } \\
\hline$\leq 18$ years & $1.11(0.91-1.36)$ \\
\hline$\geq 19$ years & 1 \\
\hline \multicolumn{2}{|l|}{ Marital status } \\
\hline Single & $0.61(0.29-1.27)$ \\
\hline Married & 1 \\
\hline Divorced & $1.40(0.93-2.11)$ \\
\hline \multicolumn{2}{|l|}{ Religious affiliation } \\
\hline Christian & 1 \\
\hline Muslim & $1.03(0.77-1.37)$ \\
\hline Traditional & $1.67(0.99-2.83)$ \\
\hline \multicolumn{2}{|l|}{ Mothers' education } \\
\hline No education & $1.63(1.21-2.19)$ \\
\hline Primary education & $1.60(1.21-2.13)$ \\
\hline Secondary or higher education & 1 \\
\hline \multicolumn{2}{|l|}{ Wealth index } \\
\hline Poor & $1.28(1.02-1.59)$ \\
\hline Middle & $0.70(0.54-0.92)$ \\
\hline Rich & 1 \\
\hline
\end{tabular}

mothers' education and community prenatal care by a doctor was associated with a $41 \%$ higher risk of dying (HR: 1.41; 95\% CI 1.21 - 1-78). A low proportion of mothers attending prenatal care by a doctor in the community was associated with 36\% (HR: 1.36; 95\% CI 1.15 - 1.86) higher risks of under-5 deaths compared with high proportions.

\section{Discussion}

This study showed that under-5 mortality was significantly associated with region of residence, with higher
Table 4 Association between community-level risk factors, under-5 mortality, and region of residence

\begin{tabular}{lc}
\hline Characteristics & OR $(95 \% \mathbf{C I})$ \\
\hline Region of residence & $1.12(0.70-1.79)$ \\
North Central & $1.29(0.79-2.12)$ \\
North East & $1.15(0.70-1.90)$ \\
North West & $0.72(0.39-1.33)$ \\
South East & $1.15(1.06-1.90)$ \\
South South & 1 \\
South West & $1.10(0.86-1.39)$ \\
Community mother's education & 1 \\
Low & $1.13(0.85-1.52)$ \\
Middle & $1.68(1.46-1.98)$ \\
High & 1 \\
Community prenatal care by doctor & $1.34(1.04-1.72)$ \\
Low & 1 \\
High & $0.66(0.44-0.98)$ \\
Community hospital delivery & \\
Low & \\
Middle & \\
High & \\
\hline
\end{tabular}

risks of under- 5 deaths for children of mothers resident in the South South region after adjusting only for individual-level risk factors and only community-level risk factors, as well as simultaneously adjusting for individual- and community-level risk factors. The risk of under -5 deaths was higher in the North East and North West regions after adjusting for child-level variables; however, these differences were reduced and became insignificant once mother-level and community-level controls were added. These elevated risks in the North East and North West regions were explained in part by differences in mothers' education, which corroborates the finding that mothers in the northern regions within this study have a higher proportion of no education or primary education. Findings in this study indicate that demographic factors such as birth order, socioeconomic factors such as marital status, mothers' education, and community-level factors such as living in communities with a low proportion of mothers that received prenatal care by a doctor are the main predictors of regional under- 5 mortality. This may be associated with spatial inequality in social development in the community within regions, which may also be associated with population density, differential levels of regional development, political and religious situations, as well as varying economic resources [32]. These factors reflect the situation in the South South region of Nigeria, which is reported to suffer from deficient social infrastructure and services (schools, roads, electricity, and health services), high unemployment, social deprivation, and endemic conflict, in spite of the region accounting for more than $90 \%$ of 
Table 5 Odds ratios and $\mathbf{9 5 \%}$ confidence intervals for individual- and community-level risk factors for under-5 mortality and region of residence

\begin{tabular}{|c|c|c|c|c|c|}
\hline Variables & Model 0 & Model 1 & Model 2 & Model 3 & Model 4 \\
\hline Fixed part & & HR $(95 \% \mathrm{Cl})$ & HR $(95 \% \mathrm{Cl})$ & HR $(95 \% \mathrm{Cl})$ & HR $(95 \% \mathrm{Cl})$ \\
\hline \multicolumn{6}{|l|}{ Region of residence } \\
\hline North Central & & $1.51(0.99-2.30)$ & $1.50(0.99-2.29)$ & $1.31(0.83-2.07)$ & $1.27(0.79-2.03)$ \\
\hline North East & & $2.41(1.63-3.57)$ & $2.35(1.59-3.49)$ & $1.49(0.94-2.26)$ & $1.38(0.83-2.29)$ \\
\hline North West & & $2.28(1.56-3.34)$ & $2.23(1.52-3.27)$ & $1.41(0.89-2.26)$ & $1.29(0.77-2.17)$ \\
\hline South East & & $1.41(0.88-2.26)$ & $1.37(0.85-2.21)$ & $0.65(0.35-1.23)$ & $0.68(0.36-1.28)$ \\
\hline South South & & $1.85(1.17-2.91)$ & $1.82(1.15-2.87)$ & $1.36(1.81-2.30)$ & $1.30(1.76-2.20)$ \\
\hline South West & & 1 & 1 & 1 & 1 \\
\hline \multicolumn{6}{|l|}{ Sex of child } \\
\hline Female & & & $1.09(0.93-1.27)$ & $1.04(0.87-1.24)$ & $1.04(0.87-1.24)$ \\
\hline Male & & & 1 & 1 & 1 \\
\hline \multicolumn{6}{|l|}{ Birth order } \\
\hline First birth (order 1) & & & $1.40(1.16-1.68)$ & $1.2(0.99-1.68)$ & $1.28(0.98-1.68)$ \\
\hline 2 - 4 birth order & & & 1 & 1 & 1 \\
\hline$\geq 5$ birth order & & & $1.44(1.16-1.80)$ & $1.64(1.24-2.18)$ & $1.64(1.24-2.17)$ \\
\hline \multicolumn{6}{|l|}{ Mother's age } \\
\hline$\leq 23$ years & & & & $1.01(0.77-1.31)$ & $1.02(0.78-1.32)$ \\
\hline $24-28$ years & & & & 1 & 1 \\
\hline$\geq 34$ years & & & & $0.84(0.62-1.13)$ & $0.84(0.62-1.14)$ \\
\hline \multicolumn{6}{|l|}{$\begin{array}{l}\text { Mother's age at birth of first } \\
\text { child }\end{array}$} \\
\hline$\leq 18$ years & & & & $1.12(0.88-1.42)$ & $1.13(0.88-1.44)$ \\
\hline$\geq 19$ years & & & & 1 & 1 \\
\hline \multicolumn{6}{|l|}{ Marital status } \\
\hline Single & & & & $0.72(0.29-1.78)$ & $0.73(0.29-1.78)$ \\
\hline Married & & & & 1 & 1 \\
\hline Divorced & & & & $1.75(1.08-2.82)$ & $1.76(1.09-2.84)$ \\
\hline \multicolumn{6}{|l|}{ Religion } \\
\hline Muslim & & & & $1.09(0.78-1.51)$ & $1.08(0.77-1.50)$ \\
\hline Traditional & & & & $1.62(0.78-3.36)$ & $1.60(0.77-3.34)$ \\
\hline Christian & & & & 1 & 1 \\
\hline \multicolumn{6}{|l|}{ Mothers' education } \\
\hline No education & & & & $2.24(1.51-3.32)$ & $2.17(1.44-3.26)$ \\
\hline Primary education & & & & $1.92(1.35-2.74)$ & $1.90(1.32-2.75)$ \\
\hline $\begin{array}{l}\text { Secondary or higher } \\
\text { education }\end{array}$ & & & & 1 & 1 \\
\hline \multicolumn{6}{|l|}{ Wealth index } \\
\hline Poor & & & & $1.27(0.98-1.63)$ & $1.23(0.95-1.59)$ \\
\hline Middle & & & & 1 & 1 \\
\hline Rich & & & & $0.85(0.62-1.17)$ & $0.89(0.64-1.22)$ \\
\hline $\begin{array}{l}\text { Cross-level interaction } \\
\text { (mother's age at birth of first } \\
\text { child \& community prenatal } \\
\text { care by doctor }\end{array}$ & & & & $0.94(0.63-1.40)$ & $1.15(0.58-1.51)$ \\
\hline $\begin{array}{l}\text { Cross-level interaction } \\
\text { (mother's education \& } \\
\text { community prenatal care by } \\
\text { doctor }\end{array}$ & & & & $1.08(0.25-1.76)$ & $1.41(1.21-1-78)$ \\
\hline \multicolumn{6}{|l|}{$\begin{array}{l}\text { Community mother's } \\
\text { education }\end{array}$} \\
\hline Low & & & & & $1.05(0.83-1.34)$ \\
\hline Middle & & & & & 1 \\
\hline High & & & & & $1.02(0.75-1.39)$ \\
\hline
\end{tabular}


Table 5 Odds ratios and $95 \%$ confidence intervals for individual- and community-level risk factors for under-5 mortality and region of residence (Continued)

\begin{tabular}{|c|c|c|c|c|c|}
\hline \multicolumn{6}{|c|}{$\begin{array}{l}\text { Community prenatal care by } \\
\text { doctor }\end{array}$} \\
\hline Low & & & & & $1.36(1.15-1.86)$ \\
\hline High & & & & & 1 \\
\hline \multicolumn{6}{|c|}{ Community hospital delivery } \\
\hline Low & & & & & $1.12(0.87-1.45)$ \\
\hline Middle & & & & & 1 \\
\hline High & & & & & $0.79(0.52-1.22)$ \\
\hline Random part & Empty & Region of residence & Child-level & Mother-level & Community-level \\
\hline ICC Mothers & 8.2 & 7.2 & 3.5 & 3.3 & 3.3 \\
\hline Variance (SE) & $0.316(0.137)$ & $0.271(0.131)^{*}$ & $0.127(0.125)$ & $0.116(0.124)$ & $0.120(0.122)$ \\
\hline ICC Communities & 6.6 & 5.3 & 5.4 & 3.3 & 3.1 \\
\hline Variance (SE) & $0.253(0.074)$ & $0.200(0.067)^{* *}$ & $0.196(0.065)^{* *}$ & $0.118(0.058)^{*}$ & $0.109(0.055)^{*}$ \\
\hline
\end{tabular}

${ }^{*} p<.05 ;{ }^{* *} p<.01 ;{ }^{* * *} p<.001$.

Nigeria's proven gas and oil reserves and the nation's wealth $[33,34]$. Geographically, the region is characterized by extensive mangrove forests and extensive networks of lagoons and swamps affected by environmental degradation from crude oil spillage and pollution. These conditions may be related with the increased risks of under- 5 deaths for children in this region.

In addition, cross-level interaction between mother's education and community prenatal care by a doctor (i. e., mothers who had no education and lived in communities with low community prenatal care) was associated with a more than twofold increase in risks of under-5 deaths. Although the specific mechanisms underlying the increased mortality are unknown, plausible explanations may include the fact that mothers with little or no education residing in communities deprived of prenatal care by a doctor are more vulnerable because they are generally poorer and lack the economic means for essential goods and services (health care, medications, and transportation) compared to mothers with higher education and access to prenatal care.

The risks of under- 5 deaths were higher for $\geq 5$ birth order. The influence of birth order on various types of child outcomes is largely dependent on the social and cultural context and may be associated with social disadvantages within families and communities [35], given that large sibships may be a marker for low socioeconomic status [36] and erosion of nutritional resources $[37,38]$. However, the influence of other unmeasured factors such as utilization of family planning services cannot be ruled out. This study also found that lower socioeconomic position (divorce, no education, primaryonly education) was associated with increased risks of under-5 deaths, which is in agreement with findings from previous studies indicating that higher socioeconomic position of individuals and populations strongly influences health-seeking behavior and is associated with better health $[39,40]$.

Furthermore, living in communities with a low percentage of mothers who received prenatal care by a doctor was associated with higher risks of under-5 deaths. This could be explained by lower access to prenatal care directly increasing the chances that mothers in the community would not utilize health care services, such as institutional delivery and immunization for their child $[41,42]$. Timely access to prenatal care by a doctor is an important preventive measure against maternal and child health outcomes such difficult or obstructed labor, postnatal bleeding, and child deaths $[43,44]$. Community prenatal care by a doctor is also an indication of the quality of care received by the mother and infant during childbirth. This association at the community level is also a reflection of socioeconomic position at the individual level because individual socioeconomic position strongly influences health-seeking behavior by enhancing mothers' perceptions of disease etiology and treatment patterns, resulting in improved health and welfare of their children. Higher socioeconomic position empowers mothers and enhances their decision-making power. Community-level variation remained significant after controlling for individual- and community-level variables, indicating that differences among communities still remain unexplained and need further exploration regarding the community-level determinants of under-5 mortality. This finding is also validated by the result of the cross-level interaction.

The intraclass correlation across communities in all the models and across mothers in Model 1 was 
significantly different from zero, implying that there are significant differences in the risks of under-5 deaths between communities in all the models and between mothers in Model 1 (with region of residence as the only explanatory variable).

The geopolitical regions of low- and middle-income countries such as Nigeria are an important sphere of influence on child survival. As such, findings show the relevance of adopting a more spatially disaggregated, community-level approach to regional policies, given that regions are usually made up of people and communities sharing similar geographical, political, socioeconomic, and cultural characteristics that either promote or inhibit health-seeking behavior and access to health care facilities.

Several limitations need to be considered when interpreting findings in this study. First, administratively defined boundaries were used as a proxy for neighborhoods or communities in this study. There is an inherent risk of nondifferentially misclassifying individuals into inappropriate administrative boundaries, which may generate information biases and reduce the validity of the analysis. Second, data on household income or expenditure, which are the indicators commonly used to measure wealth, are not routinely collected in DHS surveys. The assets-based wealth index used in this study is only a proxy indicator for individual/household economic status and may not always produce results similar to those obtained from direct assessments of income and expenditure where such data are available or can be reliably collected $[45,46]$. The strengths of this study are also worth mentioning and include: $i$ ) DHS surveys are nationally representative and enable the generalization of the results across the country; ii) the DHS variables are defined similarly across countries, and results are therefore comparable across countries [47,48]; and iii) using administrative boundaries permits the comparability of any set of DHS data on the same geographical frame, or of presenting complex data in a simple way, provided there is a good conceptual framework of the studied territory.

\section{Acknowledgements}

The author is grateful to Measure Demographic and Health Survey (ORC Macro) for the data used in this study.

\section{Conflict of interests}

The authors declare that they have no competing interests.

\section{Author details}

'Division of Global Health \& Inequalities, The Angels Trust - Nigeria, Abuja, Nigeria. ${ }^{2}$ Department of Public Health, Division of Social Medicine, Karolinska Institute, Stockholm, Sweden.

\section{Authors' contributions}

The conception, data analyses, and interpretation of results in this manuscript were done by DA
Received: 17 December 2009 Accepted: 9 March 2011

Published: 9 March 2011

\section{References}

1. WHO: The world health report 2000; health systems: improving performance. Geneva: World Health Organisation; 2000.

2. Braveman P, Gruskin S: Poverty, equity, human rights and health. Bull World Health Organ 2003, 81:539-545.

3. Victora CG, Wagstaff A, Schellenberg JA, Gwatkin D, Claeson M, Habicht JP: Applying an equity lens to child health and mortality: more of the same is not enough. Lancet 2003, 362:233-41.

4. Kalipeni E: Health and disease in southern Africa: a comparative and vulnerability perspective. Soc Sci Med 2000, 50:965-983.

5. Kloos H, Zein ZA: The ecology of health and disease in Ethiopia. Boulder, Colorado: Westview Press; 1993.

6. Labonte R, Polanyi M, Muhajarine N, Mclntosh T, Williams A: Beyond the divides: Towards critical population health research. Critical Public Health 2005, 15:5-17.

7. Siddiqi A, Irwin LG, Hertzman C: The Region as a Sphere of Influence. Total environment assessment model for early child development: Evidence report World Health Organization's Commission on the Social Determinants of Health; 2007.

8. Federal Office of Statistics [Nigeria]: Nigeria Demographic and Health Survey 1990. Lagos, Nigeria Federal Office of Statistics; 1992.

9. National Population Commission [Nigeria], ORC Macro: Nigeria Demographic and Health Survey 1999. Abuja, Nigeria: National Population Commission; 2000

10. Agunwamba A, Bloom D, Friedman A, Ozolins M, Rosenberg L, Steven D, Weston M: Nigeria: The Next Generation - Literature Review. British Council Nigeria; 2009 [http://www.nextgenerationnigeria.org/wp-content/ uploads/2009/06/NigeriaLiteratureReview-28may09-Final.pdf].

11. Antai D: Faith and Child Survival: The Role of Religion in Childhood Immunization in Nigeria. J Biosoc Sci 2009, 41:57-76.

12. Antai D, Ghilagaber G, Wedrén S, Macassa G, Moradi T: Inequities in UnderFive mortality in Nigeria: Differentials by Religious Affiliation of the Mother. J Relig Health 2009, 48:290-304.

13. Kandala NB, Ji C, Stallard N, Stranges S, Cappuccio FP: Spatial analysis of risk factors for childhood morbidity in Nigeria. Am J Trop Med Hyg 2007 77:770-779.

14. Adelekan DA: Childhood nutrition and malnutrition in Nigeria. Nutrition 2003, 19:179-181.

15. Harrison KA: Maternal mortality in Nigeria: the real issues commentary. Afr J Reprod Health 1997, 1:7-13.

16. Orubuloye IO: The demographic situation in Nigeria and prospects for fertility transition. J Int Dev 1995, 7:135-144.

17. Antai D, Antai J: Collective violence and attitudes of women toward intimate partner violence: Evidence from the Niger Delta. BMC Int Health Hum Rights 2009, 9:12.

18. National Population Commission [Nigeria], ORC Macro: Nigeria Demographic and Health Survey 2003. Calverton, Maryland, USA: National Population Commission and ORC Macro; 2004.

19. Case A, Lubotsky D, Paxson C: Economic status and health in childhood: The origins of the gradient. American Economic Review 2002, 92:1308-1334.

20. Currie J, Stabile M: Socioeconomic status and child health: Why is the relationship stronger for older children? American Economic Review 2003, 93:1813-1823.

21. Lee S-H: Demand for immunization, parental selection, and child survival: Evidence from rural India. Review of Economics of the Household 2005, 3:171-197.

22. Sugathan KS, Mishra V, Retherford RD: Promoting institutional deliveries in rural India: The role of antenatal-care services. National Family Health Survey Subject Reports, No. 20. Mumbai: Institutional Institute for Population Sciences; and Honolulu: East-West Center; 2001.

23. Khan KS, Wojdyla D, Say L, Gulmezoglu AM, Van Look PF: WHO analysis of causes of maternal death: a systematic review. Lancet 2006, 367:1066-1074.

24. World Health Organization (WHO): Maternal mortality in 2000: estimates developed by WHO, UNICEF and UNFPA. Geneva: World Health Organization; 2003

25. Diez-Roux AV: Investigating neighbourhood and area effect on health Am J Publ Health 2001, 91:783-789. 
26. Pearl M, Braveman P, Abrams B: The relationship of neighbourhood socioeconomic characteristics to birthweight among five ethnic groups in California. Am J Publ Health 2001, 91:1808-1824.

27. Parmar MKB, Machin D: Survival analysis: A practical approach. New York: John Wiley \& Sons; 1995.

28. Rabe-Hesketh S, Skrondal A: Multilevel and Longitudinal Modeling using Stata. College Station, Texas: Stata Press; 2005.

29. Merlo J, Chaix B, Yang M, Lynch J, Rastam L: A brief conceptual tutorial of multilevel analysis in social epidemiology: linking the statistical concept of clustering to the idea of contextual phenomenon. J Epidemiol Community Health 2005, 59:443-500.

30. Diez-Roux AV: Investigating neighbourhood and area effect on health Am J Publ Health 2001, 91:783-789.

31. Bullen N, Jones K, Duncan C: Modeling complexity: analyzing between individual and between-place variation - a multilevel tutorial. Environ Plann 1997, 29:585-609.

32. Nigerian Institute of Social and Economic Research (NISER): Nigerian Migration and Urbanization Survey 1993. Ibadan; 1993.

33. Eweje G: Multinational oil companies' CSR initiative in Nigeria: The scepticism of stakeholders in host communities. Managerial Law 2007, 49:218-235.

34. United Nations Development Programme (UNDP): Niger Delta Human Development Report: A History of Derivation Formula. UNDP; 2006.

35. Modin B: Birth order and mortality: a life-long follow-up of 14,200 boys and girls born in early 20th century Sweden. Soc Sci Med 2002, 54:1051-1064

36. Blaser MJ, Nomura A, Lee J, Stemmerman GN, Perez-Perez Gl: Early-life family structure and microbially induced cancer risk. PLoS Med 2007, 4:e7.

37. Das Gupta M: Death clustering, mothers' education and the determinants of child mortality in rural Punjab, India. Population Studies 1990, 44:489-505.

38. Uddin J, Hossain Z, Ullah MO: Child mortality in a developing country: A statistical analysis. Journal of Applied Quantitative Methods 2009, 3:270-283.

39. Lynch JW, Kaplan GA, Cohen RD, Kauhanen J, Wilson TW, Smith NL, Salonen JT: Do cardiovascular risk factors explain the relationship between socioeconomic status, risk of all-cause mortality, cardiovascular mortality and acute myocardial infarction? Am J Epidemiol 1996, 144:934-942.

40. Majumder AK, Shafiqul Islam SM: Socioeconomic and environmental determinants of child survival in Bangladesh. J Biosoc Sci 1993, 25:311-318.

41. Case A, Lubotsky D, Paxson C: Economic status and health in childhood: The origins of the gradient. American Economic Review 2002, 92:1308-1334.

42. Currie J, Stabile M: Socioeconomic status and child health: Why is the relationship stronger for older children? American Economic Review 2003, 93:1813-1823

43. Khan KS, Wojdyla D, Say L, Gulmezoglu AM, Van Look PF: WHO analysis of causes of maternal death: a systematic review. Lancet 2006, 367:1066-1074.

44. World Health Organization (WHO): Maternal mortality in 2000: estimates developed by WHO, UNICEF and UNFPA. Geneva: World Health Organization; 2003

45. Filmer D, Pritchett LH: Estimating wealth effects without expenditure data-or tears: an application to educational enrollments in states of India. Demography 2001, 38:115-132.

46. Montgomery MR, Gragnolati M, Burke KA, Paredes E: Measuring living standards with proxy variables. Demography 2000, 37:155-174.

47. de Walque D: Who gets AIDS and how? Education and sexual behaviors in Burkina Faso, Cameroon, Ghana, Kenya and Tanzania. Policy Research Working Paper 3844, Washington, DC, World Bank; 2006.

48. Fotso JC: Child health inequities in developing countries: differences across urban and rural areas. Int I Equity Health 2006, 5:9.

doi:10.1186/1478-7954-9-6

Cite this article as: Antai: Regional inequalities in under- 5 mortality in Nigeria: a population-based analysis of individual- and community-level determinants. Population Health Metrics 2011 9:6.

\section{Submit your next manuscript to BioMed Central and take full advantage of:}

- Convenient online submission

- Thorough peer review

- No space constraints or color figure charges

- Immediate publication on acceptance

- Inclusion in PubMed, CAS, Scopus and Google Scholar

- Research which is freely available for redistribution

Submit your manuscript at www.biomedcentral.com/submit 